\title{
Measurement complexity of adherence to medication
}

This article was published in the following Dove Press journal:

Therapeutics and Clinical Risk Management

30 March 2012

Number of times this article has been viewed

\section{Dayani Galato}

Fabiana Schuelter-Trevisol

Anna Paula Piovezan

Master Program in Health Sciences, University of Southern Santa Catarina (Unisul) Tubarão, Santa Catarina, Brazil
Correspondence: Dayani Galato Pharmacy School and Master of Health Science, University of Southern Santa Catarina, Avenida José Acácio Moreira, 787, Bairro Dehon, Tubarão,

Santa Catarina, Brazil, Cep 88704-900

Tel +55 48362 I 3363

Fax +55 4836213365

Email dayani.galato@unisul.br
Adherence to pharmacologic therapy is a major challenge for the rational use of medicines, particularly when it comes to antiretroviral drugs that require adherence to at least $95 \%$ of prescribed doses. ${ }^{1}$ Studies in this area are always important and contribute to medication adherence understanding, even though there is no reference test for measuring this. Recently, an article was published in this journal that proposes the determination of lamivudine plasma concentration to validate patient self-reported adherence to antiretroviral treatment. ${ }^{2}$ In that study, serum levels obtained after 3 hours of ingestion of the last dose of the drug were compared with patient reports that were classified into different levels of adherence, based on their recall of missed doses in the previous 7 days.

It was hypothesized by the authors that the use of a biological marker for drug adherence was extremely important, given the relevance of the topic. However, we would like to draw attention to some points that may determine the success of the use of similar methods for this purpose. The formation of groups with similar anthropometric characteristics is relevant since the dose of lamivudine may have to be changed, depending, for example, on sex, weight, and age. ${ }^{3}$ Even information considered important by the authors of that study was not provided. There is a need for greater clarity on the eligibility criteria, especially with regard to the clinical stage of the disease, CD4 counts and viral load, associated diseases, and comorbidity, as well as the evaluation of kidney function and other medications used that can affect lamivudine pharmacokinetics. ${ }^{3}$

We also point out that the dosage used must be taken into account, because differences in the bioavailability of the drug may occur if the product is being used in a single daily dose or every 12 hours, and be influenced by the amount of lamivudine that the patient is using. ${ }^{4}$ Unfortunately, this information was not provided by the authors.

Another point worth mentioning is the recall period used as reference. Depending on the nature of the study, it is currently preferred that a 24 or 48 hour period be used. With respect to this study, for instance, a 7-day period would incorporate a weekend. In Brazil, we have observed that patients on antiretroviral therapy have lower adherence to treatment on weekends. Their routine can be altered during weekends. For example, often they drink alcohol and fail to use their medication for fear of adverse drug interactions. ${ }^{5}$

Finally, the study by Minzi et $\mathrm{al}^{2}$ suggested a high agreement rate (more than $80 \%$ ) between self-reported patient adherence and antiretroviral plasma levels. However, 
further studies may be able to strengthen this hypothesis using a correlation analysis that adopts a more robust statistical method to assess medication adherence.

\section{References}

1. World Health Organization. Adherence to Long-Term Therapies: Policy for Action; Meeting Report June 4-5, 2001. Geneva: World Health Organization; 2001.

2. Minzi OM, Mugoyela V, Gustafsson LL. Correlation between lamivudine plasma concentrations and patient self-reported adherence to antiretroviral treatment in experienced HIV patients. Ther Clin Risk Manag. 2011; $7: 441-446$.
3. Johnson MA, Moore KH, Yuen GJ, Bye A, Pakes GE. Clinical pharmacokinetics of lamivudine. Clin Pharmacokinet. 1999;36(1): $41-66$.

4. Ye M, Wang L, Fu Q, Zhu Z, Li P, Li T. Steady-state pharmacokinetics of lamivudine once-daily versus twice-daily dosing in Chinese HIV-infected patients. HIV Clin Trials. 2010;11(4):230-237.

5. Melchior R, Nemes MI, Alencar TM, Buchalla CM. Desafios da adesão ao tratamento de pessoas vivendo com HIV/Aids no Brasil [Challenges of treatment adherence by people living with HIV/AIDS in Brazil]. Rev Saúde Pública. 2007;41(Suppl 2):87-93. Portuguese. 


\section{Author's response Omary Minzi}

Unit of Pharmacology and Therapeutics, School of Pharmacy, Muhimbili University of Health and Allied Sciences,

Dar Es Salaam, Tanzania

Correspondence: Omary Minzi

Unit of Pharmacology and Therapeutics, School of Pharmacy, Muhimbili

University of Health and Allied Sciences, PO Box 650I3,

Dar Es Salaam, Tanzania

Email minziobejayesu@gmail.com

We agree with some of the points raised by the reader in the letter. We also understand that the use of a drug like lamivudine, which has such a short half-life, could be misleading, especially if a patient missed a dose and then takes the medication the morning of the day blood samples are to be collected. The patient must be trusted to accurately report whether they have taken the dose at home, since there is no way to verify this.

We did not recruit the study patients but used patient data available at the clinics since we wanted to find out what happens in real life at clinics treating human immunodeficiency virus (HIV) in Tanzania. It was expected that, under normal circumstances, parameters such as liver and kidney function tests as well as body weight would be in the patient records. We did not want the patients to modify their drug-taking habits, so used information recorded by clinicians and nurses in patient records. It will be important in the future to launch a similar study under direct observation of the investigators because this would enable control over the study conditions and determine all the necessary parameters and laboratory tests. At the moment, lamivudine-based highly active antiretroviral therapy is administered 12-hourly at the HIV clinics, and the study was based on adult patients.

Given that the objective of our study was not to relate a patient's serum drug levels to their CD4 count or clinical staging, we concentrated more on information about drug intake provided by patients to our research nurses and compared this with serum lamivudine concentrations. However, we agree that the use of a 7-day recall period concerning missed doses could be unreliable. We would support the use of a period of 24-48 hours, as proposed by Galato.

Despite our encouraging findings, we are of the opinion that a similar study could be launched using a recall period of 24-48 hours and also a drug with a long half-life as a marker for adherence, as opposed to lamivudine which has a very short half-life and may not indicate a missed dose if a patient took the drug on the morning of the day the blood samples were to be collected. However, it is important to note that even drugs with a long half-life have some shortcomings when used for these types of studies. For instance, it may be difficult to identify a single missed dose during any given period after steady-state plasma levels are achieved. Further studies should be conducted to acquire data based on a 24-48 hour recall period using drugs with both long and short half-lives; of course, taking into consideration the renal and liver status of patients involved in such studies.
Therapeutics and Clinical Risk Management

\section{Publish your work in this journal}

Therapeutics and Clinical Risk Management is an international, peerreviewed journal of clinical therapeutics and risk management, focusing on concise rapid reporting of clinical studies in all therapeutic areas, outcomes, safety, and programs for the effective, safe, and sustained use of medicines. This journal is indexed on PubMed Central, CAS,

\section{Dovepress}

EMBase, Scopus and the Elsevier Bibliographic databases. The manuscript management system is completely online and includes a very quick and fair peer-review system, which is all easy to use. Visit $\mathrm{http}: / / \mathrm{www}$.dovepress.com/testimonials.php to read real quotes from published authors. 